In press, Psychology and Aging

(C)American Psychological Association, 2019. This paper is not the copy of record and may not exactly replicate the authoritative document published in the APA journal. Please do not copy or cite without author's permission. The final article is available, upon publication, at DOI: 10.1037/pag0000368

\title{
A systematic review and meta-analysis of age-related differences in trust
}

\author{
Phoebe E. Bailey and Tarren Leon \\ Western Sydney University
}

Author Note

Phoebe E. Bailey, School of Social Sciences and Psychology, Western Sydney

University, Penrith, NSW, Australia; Tarren Leon, School of Social Sciences and

Psychology, Western Sydney University, Penrith, NSW, Australia.

Correspondence concerning this article should be addressed to Phoebe E. Bailey,

School of Social Sciences and Psychology, Western Sydney University, Locked Bag 1797,

Penrith NSW 2751, AUSTRALIA. Email: p.bailey@ westernsydney.edu.au 


\begin{abstract}
This systematic review and meta-analysis quantifies the magnitude and breadth of age-related differences in trust. Thirty-eight independent data sets met criteria for inclusion. Overall, there was a moderate effect of age group on trust $(g=0.22)$, whereby older adults were more trusting than young adults. Three additional meta-analyses assessed age-related differences in trust in response to varying degrees of trustworthiness. This revealed that older adults were more trusting than young adults in response to neutral $(g=0.31)$ and negative $(g=0.33)$, but not positive ( $g=0.15$ ), indicators of trustworthiness. The effect of age group on trust in response to positive and neutral cues was moderated by type of trust (financial vs. nonfinancial) and type of responding (self-report vs. behavioral). Older adults were more trusting than young adults in response to positive and neutral indicators of trustworthiness when trust was expressed non-financially, but not financially. There was also an age-related increase in self-reported, but not behavioral, trust in response to neutral cues. Older adults were more trusting than young adults in response to negative indicators of trustworthiness regardless of the type of trust or type of responding. The reliability of information about trustworthiness did not moderate any of the effects of age group on trust. Implications of these findings and directions for future research are discussed.
\end{abstract}

Keywords: trust, trustworthiness, financial exploitation, cooperation, positivity effect 
Populations around the world are rapidly ageing and almost a quarter of people will be aged 60 or more by 2050 (United Nations, 2017). Trust may be particularly important for the successful functioning of this older cohort as they come to rely more on others in the face of physical and cognitive decline (Bookwala, 2011). Trust is defined from a multidisciplinary perspective as "a psychological state comprising the intention to accept vulnerability based on positive expectations of the intentions or behavior of another" (Rousseau, Sitkin, Burt, \& Camerer, 1998, p. 395). Whereas physical and cognitive losses with age are typically offset by gains in emotional control (Brady, Kneebone, Denson, \& Bailey, 2018), some changes are not as easily classified as a gain or loss, including trust. Trust is important for establishing and maintaining cooperation between individuals and groups, and promoting prosocial behavior, good health, life satisfaction, and longevity (Van Lange, 2015). However, it can also put individuals at risk of exploitation if left unreciprocated.

There is currently mixed evidence for age-related differences in trust. Two large multi-country (Li \& Fung, 2013) and longitudinal (Poulin \& Haase, 2015) studies have shown that trust increases with age. Other studies show no age-related change in trust (e.g., (Bailey et al., 2015, Study 2; Holm \& Nystedt, 2005; Rieger \& Mata, 2015; Sutter \& Kocher, 2007), or a decrease with age (e.g., Bond \& DePaulo, 2008; Pak, Rovira, McLaughlin, \& Baldwin, 2017). These conflicting findings are likely to be explained by the different ways in which trust is measured, as well as the way in which indicators of trustworthiness may vary.

\section{Trust as a function of trustworthiness}

There are both empirical and theoretical grounds for predicting that trust in the untrustworthy relative to trustworthy increases disproportionately with age. According to socioemotional selectivity theory, as we grow older and future time perspective decreases, motivation to achieve emotional satisfaction increases (Carstensen, Fung, \& Charles, 2003). Consistent with this theory, there is strong evidence for an age-related positivity effect 
whereby older adults are more likely to remember, and pay attention to, positive relative to negative information (Reed, Chan, \& Mikels, 2014). This positivity effect may be driven more by reduced negativity than enhanced positivity. Indeed, dynamic integration theory (Labouvie-Vief, 2003) predicts an adaptive shift with age to focus on less cognitively demanding positive relative to negative information. Similarly, the aging brain model predicts that, with age, amygdala activation decreases in response to negative stimuli but is maintained in response to positive stimuli (Cacioppo, Berntson, Bechara, Tranel, \& Hawkley, 2011). These theories are consistent with intact anticipation of a future monetary gain, but not loss, in older age (Nielsen, Knutson, \& Carstensen, 2008; Samanez-larkin et al., 2007). There is also an age-related decrease in anterior insula activation in response to untrustworthy (but not trustworthy) faces, suggesting a decline in the 'gut feelings' associated with expected risk (Castle et al., 2012). Thus, we may expect a disproportionately large age-related increase in trust in response to negative relative to positive indicators of trustworthiness.

Reliability of trustworthiness cues. An important consideration is that not all indicators of trustworthiness are reliable. First impressions of trustworthiness, typically made by evaluating facial appearance, are a superficial indicator of trustworthiness. More reliable indicators are second-hand reputational information, or the more time-consuming method of monitoring cooperation and dependability across repeated interactions (e.g., Bailey, Petridis, McLennan, Ruffman, \& Rendell, 2016). It is possible that age-related declines in cognitive function make it easier to process automatic, superficial facial indicators of trustworthiness relative to more cognitively demanding reliable indicators (Peters, Hess, Västfjäll, \& Auman, 2007). Alternatively, relative to young adults, older adults may use the extensive experience gained across their lifetime to limit the likelihood of judging someone based on their appearance. An empirical question therefore is whether any age-related difference in trust 
would be more or less evident in response to reliable relative to superficial cues to trustworthiness.

Financial vs. non-financial trust. A currently controversial issue is whether older adults are at increased risk of financial deception. Contrary to popular opinion, consumer fraud is less common among older adults than younger adults (Ross, Grossmann, \& Schryer, 2014), and therefore we may not become more trusting with age. It has since been argued that more research is needed given that one in 18 cognitively intact, community-dwelling older adults experience financial fraud and scams each year (Burnes et al., 2017). It was also noted that the prevalence of elder financial fraud is likely to be higher due to under-reporting, while the consequences are particularly great since there is limited time and capacity to recoup losses. There are a number of reasons to predict increased financial exploitation in older age. As noted, processing of negative information is reduced, potentially leading to a decline in attention to and memory for negative cues to trustworthiness. In addition, older adults provide higher subjective financial wellbeing ratings (Bailey, Petridis et al., 2016; Webb, Hine, \& Bailey, 2016), and report larger incomes (e.g., Sze, Gyurak, Goodkind, \& Levenson, 2012), relative to young adults. The combination of reduced attention to negative indicators of trustworthiness and increased wealth may lead to an age-related increase in trust when that trust can be expressed financially rather than non-financially.

Self-reported vs. behavioral trust. Another possibility is that the effect of age on trust is moderated by whether trust is expressed via self-report or behavior. Self-reports are associated with social desirability biases, and in the case of trust, people might want to appear more prosocial and trusting. Moreover, there is a correlation between increasing age and indices of socially desirable responding, suggesting that older adults try to present themselves more favorably than younger adults (Soubelet \& Salthouse, 2011). One explanation for this effect might be that older adults strive to overcome negative stereotypes of aging. On the 
contrary, there is evidence that young adults demonstrate more reputational concerns than older adults by expressing greater trust when face-to-face than anonymous (Bailey et al., 2015, Study 2). The current meta-analysis will help to disentangle whether age group differences in trust are moderated by self-reported versus behavioral responding.

\section{The current meta-analysis}

Theoretical and empirical evidence to date suggests both age-related similarities and differences in trust. The primary research question of the current systematic review and metaanalysis was whether young and older adults differ in their trust in response to positive, neutral, or negative cues to trustworthiness. Positive and negative indicators of trustworthiness included images of naturalistic or computer-generated faces with structural properties that convey trustworthiness or untrustworthiness (Bailey et al., 2015; Bailey, Petridis et al., 2016; Bell et al., 2013; Cassidy et al., 2018; Castle et al., 2012; Grainger et al., 2018; Petrican et al., 2013), explicit information that someone had behaved in a trustworthy or untrustworthy way in the past (Bailey Szczap et al., 2016), the combination of facial appearance and description of behavior (Cassidy \& Gutchess, 2015), videos or audio of people telling the truth or lying (Bond et al., 2005; Ruffman et al., 2012; Slessor et al., 2014; Stanley \& Blanchard-Fields, 2008), financial reciprocity, or lack thereof, in a repeated trust game (Bailey, Petridis et al., 2016; Rasmussen \& Gutchess, 2018; Suzuki, 2018; Webb et al., 2016), and technology that was reliable or unreliable (Ho et al., 2005; Pak et al., 2017). Further negative indicators of trustworthiness included misleading emails (Ebner et al., 2018) and false advertising (Kircanski et al., 2018). Studies that did not provide a cue to trustworthiness were coded as assessing trust in response to neutral cues. Some studies assessed trust in response to positive, neutral, and negative facial (Castle et al., 2012; Grainger et al., 2018; Zebrowitz et al., 2017, 2018) or behavioral (Rasmussen \& Gutchess, 2018) cues to trustworthiness. In these cases, where all three indicators of trustworthiness 
were examined, the neutral cue represented an indicator of trustworthiness at the mid-point between the positive and negative indicators. Potential moderators were also explored, including reliability of the cue to trustworthiness (i.e., superficial vs. reliable), type of trust (i.e., financial vs. non-financial), and type of responding (i.e., self-report vs. behavioral).

\section{Method}

This study was conducted according to the Preferred Reporting Items for Systematic Reviews and Meta-Analyses (PRISMA) guidelines (Moher, Liberati, Tetzlaff, Altman, \& The PRISMA Group, 2009).

\section{Information Sources and Search}

A computerized literature search using PsycINFO, Web of Science, and Scopus was completed 27 April, 2018. An additional search of PubMed was conducted 11 February, 2019. These searches did not apply any limitation on the year of publication. The title, keyword, and abstract search terms included: older adult*, age-related difference*, age difference*, effect* of age, age effect* AND trust*, trust game, investment game, deception, fraud, deceit, lie detection, prisoner's dilemma. The search terms were intended to capture studies that assess not only trust in response to positive and neutral indicators of trustworthiness, but also negative indicators, including fraud, deception, and lies. A manual forward and backward citation search of the final set of articles was conducted 15 February, 2019.

\section{Eligibility Criteria}

Studies were included if; (1) the research design compared a non-clinical sample of young and older adults, the older group had a mean age of at least 60 years, and the younger group had a mean age at least 30 years younger. Where more than two age groups were included in a study, only the youngest and oldest groups contributed (i.e., Ebner et al., 2018; Poulin \& Haase, 2015), (2) the paper was written in English, (3) the study presented precise 
statistics convertible to effect sizes or authors responded to requests for data, and (4) the study included a measure of trust.

\section{Data Extraction and Study Selection}

Table 1 reports the number of participants, mean age and percent male for the young and older age groups, as well as the screening test used to exclude older adults on the basis of cognitive status. Age group mean and standard deviation were extracted for the outcome of every measure of trust in each study. The first author (PB) extracted all data or contacted the corresponding and/or first author for missing data. Two attempts were made to contact authors and comparisons were excluded when data were not made available. For one comparison where means and standard deviations were not available, effect size was calculated using $t$ (i.e., Castle et al., 2012, Study 1). The first author re-extracted all data a second time to ensure $100 \%$ reliability across the two independent data files.

Two studies were excluded for asking participants which of two faces looked more trustworthy rather than providing a trust rating for each stimulus (i.e., Ethier-Majcher, Joubert, \& Gosselin, 2013; Franklin \& Zebrowitz, 2016). Two studies classified faces as trustworthy/untrustworthy or cooperative/selfish and were included (i.e., Cassidy, Boucher, Lanie, \& Krendl, 2018; Suzuki et al., 2019). One study was excluded for measuring memory for trustworthiness rather than responses to trustworthiness (i.e., Cassidy \& Gutchess, 2015, Study 1), and one for including only young adults (Sanchez, Rogers, Fisk, \& Rovira, 2014, Study 2). We also did not analyze neural activation in response to trustworthiness because these data were only supplied by two authors (i.e., Suzuki et al., 2019; Zebrowitz, Ward, Boshyan, Gutchess, \& Hadjikhani, 2018). Authors of seven studies did not supply requested data (i.e., Castle et al., 2012; Hardie \& Critchley, 2008; Liao \& Fu, 2014, Studies 1 and 2; Miller \& Bell, 2012; Pak, McLaughlin, \& Bass, 2014; Sanchez et al., 2014, Study 1). One 
study reported data for the lie detection tests in their paper but did not supply the dispositional trust ratings (i.e., Bond, Thompson, \& Malloy, 2005).

Three studies (i.e., Li \& Fung, 2013; Poulin \& Haase, 2015, Study 1; Rözer \& Volker, 2016) reported data from the World Values Survey (WVS; Inglehart et al., 2014), and two studies (i.e., Poulin \& Haase, 2015, Study 2; Robinson \& Jackson, 2001) reported data from the General Social Survey (GSS; Smith, Marsden, Hout, \& Kim, 2015). To avoid duplicating the data reported in these five individual studies, we accessed the data directly from the two surveys. We included the data from the most recent wave of each survey (i.e., Wave 6 of the WVS and the 2014 data of the GSS). We extracted data for the youngest (18-27 years) and oldest (78-87 years) age groups, as defined in Poulin and Haase (2015). We did the same for the lifespan sample in Josef et al. (2016). From the WVS we included responses to the question, "Most people can be trusted", while in the GSS we included responses to the question, "Generally speaking, would you say that most people can be trusted or that you can't be too careful in dealing with people?".

If studies reported data from a repeated trust game (i.e., Bailey, Petridis, et al., 2016; Rasmussen \& Gutchess, 2018; Suzuki, 2018; Webb et al., 2016), we analyzed the average investment in the final timeframe. In trust games we also analyzed average investment based on trustee behavior or reputation, averaged across facial expression (Bailey, Petridis, et al., 2016), facial appearance (Bailey, Szczap, et al., 2016; Suzuki, 2018), social closeness (Webb et al., 2016), or trustee age (Rasmussen \& Gutchess, 2018). One study assessed trustworthiness ratings of congruent versus incongruent facial and character description cues to trustworthiness and we included only the data relating to congruent stimuli (i.e., Cassidy \& Gutchess, 2015). Lie detection tasks asked participants to determine whether a speaker had told the truth or a lie. We extracted d prime from two of the lie detection studies that coded 'lie' as signal and 'truth' as noise (i.e., Bond et al., 2005; Sweeney \& Ceci, 2014). We 
averaged across oxytocin versus placebo administration in one study because there was no effect of this manipulation on trust (i.e., Grainger et al., 2018).

As shown in Table 1, trust responses coded as 'behavioral' included financial investments in trust games (Bailey et al., 2015; Bailey, Petridis et al., 2016; Bailey, Szczap et al., 2016; Bell et al., 2013; Holm \& Nystedt, 2005; Josef et al., 2016; Rasmussen \& Gutchess, 2018; Rieger \& Mata, 2013; Sutter \& Kocher, 2007; Suzuki, 2018; Webb et al., 2016) or a bluff-challenge game (Schniter \& Shields, 2014), area under the curve when using a mouse to classify faces as trustworthy or untrustworthy (Cassidy et al., 2018), eye gaze following (Petrican et al., 2013), and reliance on technology, including tendency to agree or disagree with an automated aid or to look at alternative options (Pak et al., 2012), perform label checks or timer checks (Ho et al., 2005, Study 1), or make errors of commission or omission (i.e., follow an incorrect instruction or not complete a task due to failure of the automated aid, respectively; Ho et al., 2005, Study 2).

Responses coded as 'self-report' included ratings of facial trustworthiness (Bailey et al., 2015; Bailey, Petridis et al., 2016; Cassidy \& Gutchess, 2015; Castle et al., 2012;

Grainger et al., 2018, Kiiski et al., 2016, Petrican et al., 2013; Suzuki, 2008; Zebrowitz et al., 2013; Zebrowitz, 2017; Zebrowitz, 2018), classification of faces as trustworthy/untrustworthy (Cassidy et al., 2018) or cooperative/selfish (Suzuki et al., 2019), dispositional ratings of trustworthiness (Bailey et al., 2015; Castle et al., 2012; Ebner et al., 2018, Komeda et al., 2018), ratings of the trustworthiness of a partner's behavior in a trust game (Bailey, Petridis et al., 2016; Webb et al., 2016), discrimination of lies from truth when listening to a speaker (Bond et al., 2005; Ruffman et al., 2012; Stanley \& Blanchard-Fields, 2008; Sweeney \& Ceci, 2014), ratings of the trustworthiness of a speaker (Slessor et al., 2014), ratings of the likelihood of clicking on a link in phishing emails (Ebner et al., 2018), or ratings of trust in technology (Ho et al., 2005; Pak et al., 2012). 


\section{Data analyses}

We first calculated an overall mean weighted effect of age (young vs. older) on trust. When an individual study included two or more measures of trust (i.e., dependent outcomes), effect sizes for each outcome were first pooled to create a composite estimate of the effect of age group on trust. The composite was calculated accounting for a conservative correlation of 1.0 between measures. Thus, only a single composite effect was permitted to contribute from each independent dataset. Next, to assess the effect of trustworthiness on age-related differences in trust, the mean weighted effects of age (young vs. older) on trust were calculated in response to positive, neutral, and negative cues to trustworthiness. If a study reported data on more than one measure of trust in response to positive, neutral, or negative indicators of trustworthiness, we first computed a composite effect size accounting for a conservative correlation of 1.0 between measures.

Across the four meta-analyses, the standardized mean difference (Hedge's $g ; 0.2=$ small, $0.5=$ medium, and $0.8=$ large) was used as the effect size summary statistic to prevent biased estimates from studies with small sample sizes. A random-effects model was used to allow for population parameters to vary across studies, and to allow the findings to generalize beyond the specific studies included in the present meta-analysis (Borenstein, Hedges, Higgins, \& Rothstein, 2009; Field \& Gillett, 2010). Heterogeneity among effect sizes was examined using the $I^{2}$ statistic (i.e., the proportion of total variability in an effect size that is due to true heterogeneity rather than sampling error). Higgins, Thompson, Deeks, and Altman (2003) define heterogeneity as low $\left(I^{2}=25 \%\right)$, moderate $\left(I^{2}=50 \%\right)$, or high $\left(I^{2}=75 \%\right)$. Positive effects represent greater expression of trust among older adults relative to young adults, and negative effects represent the opposite.

The next step was to test whether some of the heterogeneity could be explained by moderators including, reliability of the cue to trustworthiness (i.e., superficial vs. reliable), 
type of trust (financial vs, non-financial), and type of responding (self-report vs. behavioral). If more than one effect from a single dataset contributed to a single moderator level, the composite effect was first calculated using a conservative correlation of 1.0. Where a single dataset contributed to both levels of a moderator we divided $N$ by two to reduce the impact on the overall effect size. All analyses were carried out using Comprehensive Meta-Analysis Version 3.3.07 (CMA; Borenstein, Hedges, Higgins, \& Rothstein, 2014).

\section{Publication Bias and Outliers}

The trim and fill method (Duval \& Tweedie, 2000) was used to identify potential publication bias. After imputing missing studies to form a symmetrical funnel plot, this method provides an estimate of the true mean and variance. Outliers were defined as effect sizes with a standardized residual $z$ score greater than 3 (Viechtbauer \& Cheung, 2010). However, no outliers were identified using this criterion.

\section{Results}

\section{Study Selection and Characteristics}

The initial literature search resulted in 674 articles in Scopus, 349 in PsycINFO and 630 in Web of Science. After merging the three databases, 637 duplicates were removed. We also removed five non-English articles, leaving a total of 1,011 articles to review. A further 979 articles were removed based on eligibility criteria. A further seven conference proceedings or dissertations were excluded due to risks that they may contain data that are preliminary or duplicated elsewhere (see Ferguson \& Brannick, 2012). The PubMed search resulted in 396 articles. Seven were duplicates and a further 387 were removed based on eligibility criteria. The forward and backward citation search identified an additional ten articles for inclusion. The resulting 37 articles included 41 independent studies, five of which were replaced with one comparison from the GSS and one from the WVS. Thus, a total of 38 independent data sets, comprising of 23,235 young adults and 3,359 older adults were 
included in analyses. Note that the WVS alone included 21,323 young adults and 1,775 older adults. The remaining studies contributed 1,912 young adults and 1,764 older adults.

Characteristics of each study are presented in Table 1 and are indicated by an asterix in the reference section.

\section{Overall effect of age group on trust}

The overall mean weighted effect size was moderately positive in magnitude, $k=38$, $g=0.22,95 \%$ CI: $(0.13,0.32), z=4.51, p<.001^{1}$. Thus, overall, older adults were significantly more trusting than young adults. However, there was also moderate to high heterogeneity among the studies contributing to this effect, $I^{2}=62.75$. The trim and fill method did not result in any imputed comparisons to correct asymmetry in the funnel plot and therefore potential publication bias should not reduce confidence in the findings. Power analysis shows that we have more than $90 \%$ power to detect a small effect $(d=0.2)$ based on $k=38$ and an average sample size of 100, regardless of the degree of heterogeneity (Valentine et al., 2010).

\section{Trust as a function of trustworthiness}

We analyzed the mean weighted effect of age on responding to positive, neutral, and negative indicators of trustworthiness. There was no effect of age in response to positive indicators, $k=20, g=0.16,95 \% \mathrm{CI}:(-0.08,0.39), Z=1.32, p=.186$, and heterogeneity was high, $I^{2}=79.40$ (see Figure 1A). Older adults were more trusting than young adults in response to neutral indicators, $k=22, g=0.31,95 \% \mathrm{CI}$ : $(0.17,0.46), Z=4.20, p<.001$, with high heterogeneity, $I^{2}=71.30$, and negative indicators, $k=25, g=0.33,95 \%$ CI: $(0.17,0.49)$, $Z=4.11, p<.001$, with high heterogeneity, $I^{2}=70.65$ (see Figure $1 \mathrm{~B}$ ). The trim and fill procedure identified no missing studies assessing trust in response to positive or neutral indicators of trustworthiness. The data relating to negative indicators remained significant following trim and fill, $g=0.26,95 \% \mathrm{CI}$ : $(0.10,0.42)$. Power analysis shows that we have 
more than $80 \%$ power to detect a small effect $(d=0.2)$ based on $k=20$ and an average sample size of 80, regardless of the degree of heterogeneity (Valentine et al., 2010).

The following analyses examined whether reliability of the cue to trustworthiness (superficial vs. reliable), type of trust (financial vs. non-financial), and type of response (behavioral vs. self-reported) moderated the effect of age group on trust in response to positive, neutral, or negative indicators of trustworthiness. Consistent with Sisk, Burgoyne, Sun, Butler, and Macnamara (2018) we required at least five effect sizes to contribute to each level of a moderator before performing moderator analyses (see Table 2 for number of effect sizes per level).

Superficial vs. reliable cues to trustworthiness. There was no effect of reliability (superficial vs. reliable) for positive, $Q(1)=2.02, p=.155$, or negative indicators of trustworthiness, $Q(1)=0.00, p=.964$. Neutral indicators were excluded from this analysis as they cannot be classified as reliable or superficial.

Financial vs. non-financial trust. Type of trust influenced the effect of age group on trust in response to positive indicators of trustworthiness, $Q(1)=4.53, p=.033$. Specifically, there was an age-related increase in non-financial trust, $g=.29,95 \% \mathrm{CI}:(0.05,0.53)$, but not financial trust, $g=-0.33,95 \% \mathrm{CI}:(-0.84,0.19)$. Type of trust also influenced the effect of age group on trust in response to neutral indicators, $Q(1)=9.16, p=.002$. Again, there was an age-related increase in non-financial trust, $g=0.43,95 \% \mathrm{CI}:(0.26,0.60)$, but not financial trust, $g=-0.03,95 \% \mathrm{CI}:(-0.28,0.22)$. Type of trust did not influence the effect of age group on trust in response to negative indicators of trustworthiness, $Q(1)=3.68, p=.055$.

Behavioral vs. self-reported trust. Type of response did not influence the effect of age group on trust in response to positive, $Q(1)=0.97, p=.325$, or negative indicators of trustworthiness, $Q(1)=1.24, p=.266$. However, as shown in Figure 2, type of response did influence the effect of age on trust in response to neutral indicators, $Q(1)=11.69, p=.001$. 
There was no effect of age group for the behavioral data, $g=-0.02,95 \% \mathrm{CI}:(-0.22,0.18)$. However, older adults self-reported being more trusting than young adults, $g=0.45,95 \% \mathrm{CI}$ : $(0.27,0.62)$.

\section{Discussion}

The present systematic review and meta-analysis shows that although there is an agerelated increase in trust, there is heterogeneity in this effect. Most notably, older adults showed greater trust than young adults when presented with negative indicators of trustworthiness or in non-financial expressions of trust in response to positive indicators of trustworthiness. Older adults were also more trusting than young adults in response to neutral indicators of trustworthiness, however, this was only evident in their self-reported and nonfinancial trust. The reliability of the cue to trustworthiness did not influence the effect of age group on trust.

\section{An age-related increase in trust}

Relative to young adults, older adults were more trusting of the untrustworthy regardless of whether trust was expressed via self-report versus behavior or financially versus non-financially. The reliability of the cue to trustworthiness also did not influence the agerelated increase in trust in response to negative indicators of trustworthiness. Thus, the moderators examined in the current meta-analysis were unable to explain the high degree of heterogeneity among studies contributing to this effect. Nevertheless, these data support an age-related positivity effect in relation to the expression of trust (Reed et al., 2014). Indeed, there was also an age-related increase in trust in response to positive indicators of trustworthiness when that trust was expressed non-financially. This greater non-financial trust in the trustworthy is consistent with socioemotional selectivity theory and the prioritization of emotionally meaningful goals as future time perspective decreases (Carstensen et al., 2003). Greater trust in the trustworthy among older relative to young adults is likely to enhance 
interpersonal connections in older age, which in turn confers physical and psychological benefits (Li \& Fung, 2013).

Interestingly, financial expressions of trust were greater among older adults than young adults only in response to negative indicators of trustworthiness. This reduced negativity rather than increased positivity is predicted by dynamic integration theory (Labouvie-Vief et al., 2003) and the aging brain model (Cacioppo et al., 2011). Dynamic integration theory recognises that more cognitive resources are required when processing negative relative to positive information. Age-related declines in cognition should therefore inhibit older adults' processing of negative relative to positive cues to trustworthiness. However, fewer than half of the studies included in our meta-analysis reported years of education, and although many studies included measures of cognition, the type of measure was inconsistent across studies. It was therefore not possible to assess the influence of education or cognition on age-related differences in trust. This will be an important consideration for future research. Similarly, more research is needed to clarify neural underpinnings of age-related differences in trust. It has recently been shown that older adults do not experience the same heightened amygdala activation to untrustworthy relative to neutral and trustworthy-looking faces, as typically demonstrated by young adults (Zebrowitz, 2018). A further study has highlighted the importance of investigating regions of the brain associated with the processing of rewards. When someone behaves in way that is consistent with your first impression of them it activates reward-related regions such as the striatum that potentially reflect the positive feeling elicited from believing that you have good social cognitive ability. Relative to their younger counterparts, older adults experience reduced striatal response to impression-incongruent feedback (Suzuki et al., 2019). It was suggested that increased motivation to cooperate and act in a prosocial way in older age might lead to 
greater frustration when older adults learn that their initial perceptions of trustworthiness are inaccurate.

Reduced processing of negative information such as untrustworthiness is consistent with other decision-making research that has identified reduced anticipation of a future monetary loss but intact gain anticipation among older adults (e.g., Nielsen et al., 2008; Samanez-Larkin et al., 2007). Further research is needed to better understand the age-related positivity effect, and specifically reduced negativity, in financial expressions of trust. It may be that financial generosity in response to the trustworthy remains high throughout the lifespan. Indeed, there was no age-related difference in financial trust in response to positive indicators of trustworthiness. Increased financial wellbeing among older relative to young adults (Bailey, Petridis et al., 2016; Webb et al., 2016) may also mean that younger adults are more cautious than older adults when making financial investments in the untrustworthy. Regardless of the underlying mechanism, these findings are important in suggesting a heightened risk of financial exploitation and abuse in older age. As noted, one in 18 neurotypical older adults experience financial fraud and scams each year (Burnes et al., 2017). Financial abuse of older adults is also one of the fastest growing crimes (World Health Organisation, 2015). The current data show that in addition to the negative effects of increased financial trust in the untrustworthy, older adults may not benefit from increased financial trust in the trustworthy.

The current meta-analysis identified greater self-reported, but not behavioral, trust in response to neutral cues to trustworthiness among older adults relative to young adults. It has previously been shown that socially desirable responding is more prevalent among older adults than younger adults (Soubelet \& Salthouse, 2011), and older adults may therefore report greater trust because they deem this to be a socially desirable trait. However, the young and older adults did not differ in their self-reported trust in response to positive indicators of 
trustworthiness. One potential explanation is that both age groups deem trust in the trustworthy to be a desirable trait, while trust in response to neutral indicators of trustworthiness (i.e., when the trustworthiness of the recipient of trust is unknown) is deemed desirable only by older cohorts. The greater self-reported trust in response to neutral cues among older adults relative to young adults might also reflect the disproportionate contribution of studies assessing the financial expression of trust in the behavioral data. Older adults were more trusting than young adults in response to neutral indicators of trustworthiness when the trust was expressed non-financially, but not when expressed financially. These data further suggest that financial trust may be high in young adulthood except when interacting with the untrustworthy.

The current data do not suggest that reliability of the cue to trustworthiness influences age-related similarities or differences in trust. The superficial stimuli in the current metaanalysis consisted solely of faces, and facial appearances of trustworthiness are processed more automatically than other more reliable non-facial information about trustworthiness (Bailey, Szczap, et al., 2016). One prediction therefore was that cognitive decline might make it easier for older adults to process facial relative to non-facial cues (Peters et al., 2007). The alternative prediction was that older adults might be more likely than young adults to use their lifetime of experiences to avoid judging a person by their appearance. However, these effects were not evidenced and it appears that responses to superficial indicators of trustworthiness may provide a useful proxy for estimating age-related similarities or differences in trust in response to more reliable cues.

\section{Limitations and future directions}

It will be important to identify moderators of the effect of age group on trust in the untrustworthy given the high degree of heterogeneity among studies contributing to this effect. As noted, the moderators assessed in the current meta-analysis did not explain any of 
this heterogeneity, including type of trust (financial vs. non-financial), type of responding (self-report vs. behavioral), and reliability of the cue to trustworthiness (superficial vs. reliable). It is also possible that the other effects of age group on trust were moderated by additional variables that we were unable to test due to the small number of studies to date that have assessed specific potential moderators. For instance, trustee age may result in own-age biases in trust (e.g., Bailey et al., 2015), or alternatively, greater generosity extended from older to younger generations (Bailey, Ruffman, \& Rendell, 2013). It has also been shown that the age-related variance in trust is smaller for close relative to distant social contacts (e.g., Li \& Fung, 2013; Webb et al., 2016). Li and Fung (2013) explain that it may be because trust towards close social partners remains high throughout the lifespan. Studies in the current meta-analysis control for potential effects of gender by including, on average, approximately $50 \%$ of each gender within in each age group. However, future studies are needed that assess whether older males and females differ in their propensity to trust. There also need to be more studies conducted outside of the laboratory to determine whether real-world versus labbased settings moderate the effect of age on trust. Similarly, to better understand the role of trust in elder financial exploitation, researchers could begin examining older adults who have experienced financial deception in the past.

In studies using the trust game, trust is expressed financially with the expectation of financial reciprocity. Since income and financial wellbeing are reduced among young adults relative to older adults (Bailey, Petridis et al., 2016; Webb et al., 2016; Sze et al., 2012), young adults may have increased motivation to achieve financial rewards. This in turn may at least partially explain why there was an age-related increase in non-financial, but not financial, trust in response to positive and neutral indicators of trustworthiness. That is, young adults may have increased their level of trust when they expected to receive a financial reward. It is also the case that social and emotional goals become more important with age 
(Carstensen et al., 2003) and older adults might therefore be more trusting in response to social relative to financial rewards. Future research should directly examine how age-related differences in motivation to attain financial versus social rewards affects the expression of trust. Future studies should also include more diverse samples of young and older adults to include non-student young adults with higher incomes, and older adults who are less well-off. Although some studies have found older adults to report higher incomes and better financial wellbeing than young adults, Wilkins and Lass (2018) show that poverty rates are highest among the elderly, and particularly single older people. However, they also note that their income poverty measure does not take into account increased levels of home ownership among older adults relative to younger adults. A more nuanced account of the relative financial security of each age group will benefit future research.

It will also be important for future research to examine interpersonal versus humanmachine interactions as potential moderators of the effect of age on trust. According to Muir (1987, 1994), predictability and dependability of technology, along with a user's faith in it, determine the level of trust. When technology is reliable, complex decision-making is improved, which increases productivity and independence. It follows that distrust of reliable technology can lead to its rejection and loss of the potential benefits. This may be particularly the case for older adults who have less experience and less confidence in using technology relative to their younger counterparts (Vaportzis, Clausen, \& Gow, 2017). The extent to which this and any other age-related change in trust may be explained as a cohort effect versus a developmental trend should also be assessed. It is possible that any age group differences identified are at least partially due to the different time periods that the young and older adults grew up in. For example, it has been suggested that older adults are more trusting than they should be because they were brought up to believe that it is impolite to say no (Ross et al., 2004). The only existing longitudinal study of trust and aging showed a developmental 
trend whereby trust increases across a four-year period for adults ranging from 18 to 87 years (Poulin \& Haase, 2015). However, the study assessed only dispositional self-reports of trust. In the future it will be important to conduct longitudinal behavioral assessments of trust, particularly in response to negative indicators of trustworthiness.

\section{Conclusion}

In conclusion, age-related changes in trust may be classed as either gains or losses depending on the trustworthiness of the trustee. The present meta-analysis indicates greater trust among older adults relative to younger adults in response to negative indicators of trustworthiness regardless of the type of task (self-report vs. behavioral) or the type of trust (financial vs. non-financial). Expressions of trust are also greater among older adults relative to younger adults in response to positive and neutral indicators of trustworthiness, but only when expressed non-financially. Under no circumstances were young adults more trusting than older adults. Overall, these data suggest that both gains and losses can be expected as a consequence of increased trust in older age. Losses associated with older adults' increased financial investment in the untrustworthy are of great concern when there is limited time and opportunity to recover. These losses are compounded by a lack of increased financial trust in the trustworthy. However, there is evidence for greater non-financial trust in the trustworthy which represents an important gain in later life when motivation to cooperate and enhance social bonds is greater. 


\section{Footnotes}

${ }^{1}$ Excluding the World Values Survey did not change the pattern of results for this mean effect or any other mean effect that included this dataset. 


\section{References}

*Bailey, P. E., Petridis, K., McLennan, S. N., Ruffman, T., \& Rendell, P. G. (2016). Agerelated preservation of trust following minor transgressions. The Journals of Gerontology Series B: Psychological Sciences and Social Sciences, Advance online publication. https://doi.org/10.1093/geronb/gbw141

*Bailey, P. E., Rieger, M., Moustafa, A. A., Slessor, G., Rendell, P. G., \& Ruffman, T. (2015). Trust and trustworthiness in young and older adults. Psychology and Aging, 30. https://doi.org/10.1037/a0039736

Bailey, P. E., Ruffman, T., \& Rendell, P. G. (2013). Age-related differences in social economic decision making: The Ultimatum Game. Journals of Gerontology Series B: Psychological Sciences and Social Sciences, 68, 356-363. https://doi.org/10.1093/geronb/gbs073.

*Bailey, P. E., Szczap, P., McLennan, S. N., Slessor, G., Ruffman, T., \& Rendell, P. G. (2016). Age-related similarities and differences in first impressions of trustworthiness. Cognition and Emotion, 30, 1017-1026.

https://doi.org/10.1080/02699931.2015.1039493

*Bell, R., Giang, T., Mund, I., \& Buchner, A. (2013). Memory for reputational trait information: Is social-emotional information processing less flexible in old age? Psychology and Aging, 28, 984-995. https://doi.org/10.1037/a0034266

Bond, C. F., \& DePaulo, B. M. (2008). Individual differences in judging deception: Accuracy and bias. Psychological Bulletin, 134, 477-492. https://doi.org/10.1037/00332909.134.4.477

*Bond, G. D., Thompson, L. A., \& Malloy, D. M. (2005). Vulnerability of older adults to deception in prison and nonprison contexts. Psychology and Aging, 20, 60-70. https://doi.org/10.1037/0882-7974.20.1.60 
Bookwala, J. (2011). Marital quality as a moderator of the effects of poor vision on quality of life among older adults. Journals of Gerontology - Series B Psychological Sciences and Social Sciences, 66, 605-616. https://doi.org/10.1093/geronb/gbr091

Borenstein, M., Hedges, L., Higgins, J., \& Rothstein, H. (2014). Comprehensive metaanalysis version 3.3.07. Englewood, NJ: Biostat.

Borenstein, M., Hedges, L. V, Higgins, J. T., \& Rothstein, H. R. (2009). Introductionto MetaAnalysis. Chichester, UK: John Wiley and Sons. https://doi.org/10.1016/B978-0-24081203-8.00002-7

Brady, B., Kneebone, I. I., Denson, N., \& Bailey, P. E. (in press). Systematic review and meta-analysis of age-related differences in instructed emotion regulation success. PeerJ.

Burnes, D., Henderson, C. R., Sheppard, C., Zhao, R., Pillemer, K., \& Lachs, M. S. (2017). Prevalence of financial fraud and scams among older adults in the United States: A systematic review and meta-analysis. American Journal of Public Health, 107, 1295. https://doi.org/10.2105/AJPH.2017.303821a

Cacioppo, J. T., Berntson, G. G., Bechara, A., Tranel, D., \& Hawkley, L. C. (2011). Could an aging brain contribute to subjective well-being?: The value added by a social neuroscience perspective. In A. Todorov, S. Fiske, \& D. Prentice (Eds.), Social Neuroscience: Toward Understanding the Underpinnings of the Social Mind (pp. 1-23). Oxford University Press. https://doi.org/10.1093/acprof

Carstensen, L. L., Fung, H. H., \& Charles, S. T. (2003). Socioemotional selectivity theory and the regulation of emotion in the second half of life. Motivation and Emotion, 27, 103-123. https://doi.org/10.1023/A:1024569803230

*Cassidy, B. S., Boucher, K. L., Lanie, S. T., \& Krendl, A. C. (2018). Age effects on trustworthiness activation and trust biases in face perception. The Journals of Gerontology, Series B: Psychological Sciences, Advance online publication. 
https://doi.org/10.1093/geronb/gby062

*Cassidy, B. S., \& Gutchess, A. H. (2015). Influences of appearance-behaviour congruity on memory and social judgements. Memory, 23, 1039-1055.

https://doi.org/10.1080/09658211.2014.951364

*Castle, E., Eisenberger, N. I., Seeman, T. E., Moons, W. G., Boggero, I. A., Grinblatt, M. S., \& Taylor, S. E. (2012). Neural and behavioral bases of age differences in perceptions of trust. Proceedings of the National Academy of Sciences of the United States of America, 109, 20848-20852. https://doi.org/10.1073/pnas.1218518109

Duval, S., \& Tweedie, R. (2000). Trim and fill: A simple funnel-plot-based method of testing and adjusting for publication bias in meta-analysis. Biometrics, 56, 455-463.

*Ebner, N. C., Ellis, D. M., Lin, T., Rocha, H. A., Yang, H., Dommaraju, S., ... Oliveira, D. S. (2018). Uncovering susceptibility risk to online deception in aging. The Journals of Gerontology, Series B: Psychological Sciences, Advance online.

https://doi.org/10.1093/geronb/gby036

Ethier-Majcher, C., Joubert, S., \& Gosselin, F. (2013). Reverse correlating trustworthy faces in young and older adults. Frontiers in Psychology, 4, 1-7. https://doi.org/10.3389/fpsyg.2013.00592

Ferguson, C. J., \& Brannick, M. T. (2012). Publication bias in psychological science: Prevalence, methods for identifying and controlling, and implications for the use of meta-analyses. Psychological Methods, 17, 120-128. https://doi.org/10.1037/a0024445

Field, A. P., \& Gillett, R. (2010). How to do a meta-analysis. British Journal of Mathematical and Statistical Psychology, 63, 665-694. https://doi.org/10.1348/000711010X502733

Franklin, R. G., \& Zebrowitz, L. A. (2016). The influence of political candidates' facial appearance on older and younger adults' voting choices and actual electoral success. Cogent Psychology, 3, 1-12. https://doi.org/10.1080/23311908.2016.1151602 
*Grainger, S. A., Henry, J. D., Steinvik, H. R., \& Vanman, E. J. (2018). Intrnasal oxytocin does not alter initial perceptions of facial trustworthiness in younger or older adults. Journal of Psychopharmacology. http://journals.sagepub.com/doi/10.1177/0269881118806303

Hardie, E. A., \& Critchley, C. R. (2008). Public perceptions of Australia's doctors, hospitals and health care systems. Medical Journal of Australia, 189, 210-214.

Higgins, J. P. T., Thompson, S. G., Deeks, J. J., \& Altman, D. G. (2003). Measuring inconsistency in meta-analyses. British Medical Journal, 327, 557-560. https://doi.org/10.1136/bmj.327.7414.557

*Ho, G., Wheatley, D., \& Scialfa, C. T. (2005). Age differences in trust and reliance of a medication management system. Interacting with Computers, 17, 690-710. https://doi.org/10.1016/j.intcom.2005.09.007

*Holm, H., \& Nystedt, P. (2005). Intra-generational trust - A semi-experimental study of trust among different generations. Journal of Economic Behavior and Organization, 58, 403419. https://doi.org/10.1016/j.jebo.2003.10.013

*Inglehart, R. C., Haerpfer, A., Moreno, C., Welzel, K., Kizilova, J., Diez-Medrano, M., ... Al., E. (2014). World Values Survey: Round Six - Country-Pooled Datafile Version: http://www.worldvaluessurvey.org/WVSDocumentationWV6.jsp. Madrid: JD Systems Institute.

*Josef, A. K., Richter, D., Samanez-Larkin, G. R., Wagner, G. G., Hertwig, R., \& Mata, R. (2016). Stability and change in risk-taking propoensity across the adult life span. Journal of Personality and Social Psychology, 111, 430-450. http://dx.doi.org/10.1037/pspp0000090

*Kiiski, H. S. M., Cullen, B., Clavin, S. L., \& Newell, F. N. (2016). Perceptual and Social Attributes Underlining Age-Related Preferences for Faces. Frontiers in Human 
Neuroscience, 10, 1-14. https://doi.org/10.3389/fnhum.2016.00437

*Kircanski, K., Notthoff, N., DeLiema, M., Samanez-Larkin, G. R., Shadel, D., Mottola, G., ... Gotlib, I. H. (2018). Emotional arousal may increase susceptibility to fraud in older and younger adults. Psychology and Aging, 33, 325-337. https://doi.org/10.1037/pag0000228

*Komeda, H., Eguchi, Y., Kusumi, T., Kato, Y., Narumoto, J., \& Mimura, M. (2018). Decision-making based on social conventional rules by elderly people. Frontiers in Psychology, 9: 1412. https://doi.org/10.3389/fpsyg.2018.01412

Labouvie-Vief, G. (2003). Dynamic integration : Affect, cognition, and the self in adulthood. Current Directions in Psychological Science, 2, 201-206.

Li, T., \& Fung, H. H. (2013). Age differences in trust: An investigation across 38 countries. Journals of Gerontology - Series B Psychological Sciences and Social Sciences, 68, 347-355. https://doi.org/10.1093/geronb/gbs072

Liao, Q. V., \& Fu, W. (2014). Age differences in credibility judgments of online health information. ACM Transactions on Computer-Human Interaction, 21, 1-23. https://doi.org/10.1145/2534410

Miller, L. M. S., \& Bell, R. A. (2012). Online health information seeking: The influence of age, information trustworthiness, and search challenges. Journal of Aging and Health, 24, 525-541. https://doi.org/10.1177/0898264311428167

Moher, D., Liberati, A., Tetzlaff, J., Altman, D. G., \& Group, T. P. (2009). Preferred reporting items for systematic reviews and meta-analyses: The PRISMA statement. PLOS Medicine, 6, 1-6. https://doi.org/10.1371/journal.pmed.1000097

Muir, B. M. (1987). Trust between humans and machines, and the design of decision aids. International Journal of Man-Machine Studies, 27, 527-539. https://doi.org/10.1016/S0020-7373(87)80013-5 
Muir, B. M. (1994). Trust in automation: Part I. Theoretical issues in the study of trust and human intervention in automated systems. Ergonomics, 37, 1905-1922. https://doi.org/10.1080/00140139408964957

Nielsen, L., Knutson, B., \& Carstensen, L. L. (2008). NIH Public AccessAffect dynamics, affective forecasting, and aging. Emotion, 8, 318-330. https://doi.org/10.1037/15283542.8.3.318.Affect

*Pak, R., Fink, N., Price, M., Bass, B., \& Sturre, L. (2012). Decision support aids with anthropomorphic characteristics influence trust and performance in younger and older adults. Ergonomics, 55, 1059-1072. https://doi.org/10.1080/00140139.2012.691554

Pak, R., McLaughlin, A. C., \& Bass, B. (2014). A multi-level analysis of the effects of age and gender stereotypes on trust in anthropomorphic technology by younger and older adults. Ergonomics, 57, 1277-1289. https://doi.org/10.1080/00140139.2014.928750

*Pak, R., Rovira, E., McLaughlin, A. C., \& Baldwin, N. (2017). Does the domain of technology impact user trust? Investigating trust in automation across different consumer-oriented domains in young adults, military, and older adults. Theoretical Issues in Ergonomics Science, 18, 199-220. https://doi.org/10.1080/1463922X.2016.1175523

Peters, E., Hess, T. M., Västfjäll, D., \& Auman, C. (2007). Adult Age Differences in Dual Information Processes: Implications for the Role of Affective and Deliberative Processes in Older Adults' Decision Making. Perspectives on Psychological Science, 2, 1-23. https://doi.org/10.1111/j.1745-6916.2007.00025.x

*Petrican, R., English, T., Gross, J. J., Grady, C., Hai, T., \& Moscovitch, M. (2013). Friend or foe? Age moderates time-course specific responsiveness to trustworthiness cues. Journals of Gerontology - Series B Psychological Sciences and Social Sciences, 68, 215-223. https://doi.org/10.1093/geronb/gbs064 
Poulin, M. J., \& Haase, C. M. (2015). Growing to trust: Evidence that trust increases and sustains well-being across the life span. Social Psychological and Personality Science, 6, 614-621. https://doi.org/10.1177/1948550615574301

*Rasmussen, E. C., \& Gutchess, A. (2018). Can’t read my broker face: Learning about trustworthiness with age. The Journals of Gerontology, Series B: Psychological Sciences, Advance online publication. https://doi.org/10.1093/geronb/gby012

Reed, A. E., Chan, L., \& Mikels, J. A. (2014). Meta-analysis of the age-related positivity effect: Age differences in preferences for positive over negative information. Psychology and Aging, 29, 1-15. https://doi.org/10.1037/a0035194

*Rieger, M., \& Mata, R. (2015). On the generality of age differences in social and nonsocial decision making. Journals of Gerontology Series B-Psychological Sciences and Social Sciences, 70, 200-212. https://doi.org/10.1093/geronb/gbt088

Robinson, R. V., \& Jackson, E. F. (2001). Is trust in others declining in America? An ageperiod-cohort analysis. Social Science Research, 30, 117-145. https://doi.org/10.1006/ssre.2000.0692

Ross, M., Grossmann, I., \& Schryer, E. (2014). Contrary to psychological and popular opinon, there is no compelling evidence that older adults are disproportionately victmised by consumer fraud. Perspectives on Psychological Science, 9, 427-442. https://doi.org/10.1177/1745691614535935

Rousseau, D. M., Sitkin, S. B., Burt, R. S., \& Camerer, C. (1998). Not so different after all: A cross-discipline view of trust. Academy of Management Review, 23, 393-404. https://doi.org/10.5465/AMR.1998.926617

Rözer, J. J., \& Volker, B. (2016). Does income inequality have lasting effects on health and trust? Social Science and Medicine, 149, 37-45. https://doi.org/10.1016/j.socscimed.2015.11.047 
*Ruffman, T., Murray, J., Halberstadt, J., \& Vater, T. (2012). Age-related differences in deception. Psychology and Aging, 27, 543-549. https://doi.org/10.1037/a0023380

Samanez-larkin, G. R., Gibbs, S. E. B., Khanna, K., Nielsen, L., L, L., \& Hall, J. (2007). Anticipation of monetary gain but not loss in healthy older adults. Nature Neuroscience, $10,787-791$.

Sanchez, J., Rogers, W. A., Fisk, A. D., \& Rovira, E. (2014). Understanding reliance on automation: Effects of error type, error distribution, age and experience. Theoretical Issues in Ergonomics Science, 15, 134-160.

https://doi.org/10.1080/1463922X.2011.611269

*Schniter, E., \& Shields, T. W. (2014). Journal of Behavioral and Experimental Economics Ageism, honesty, and trust. Journal of Behavioral and Experimental Economics, 51, 19-29. https://doi.org/10.1016/j.socec.2014.03.006

Sisk, V. F., Burgoyne, A. P., Sun, J., Butler, J. L., \& Macnamara, B. N. (2018). To what extent and under which circumstances are growth mind-sets important to academic achievement? Two meta-analyses. Psychological Science, 29, 549-571. https://doi.org/10.1177/0956797617739704

*Slessor, G., Phillips, L. H., Ruffman, T., Bailey, P. E., \& Insch, P. (2014). Exploring ownage biases in deception detection. Cognition and Emotion, 28, 493-506. https://doi.org/10.1080/02699931.2013.839438

*Smith, T. W., Marsden, P., Hout, M., \& Kim, J. (2015). General social surveys. General Social Surveys, 1972-2014. Chicago, IL: National Opinion Research Center.

Soubelet, A., \& Salthouse, T. A. (2011). Influence of social desirability on age differences in self-reports of mood and personality. Journal of Personality, 79, 741-762. https://doi.org/10.1111/j.1467-6494.2011.00700.x

*Stanley, J. T., \& Blanchard-Fields, F. (2008). Challenges Older Adults Face in Detecting 
Deceit: The Role of Emotion Recognition. Psychology and Aging, 23, 24-32. https://doi.org/10.1037/0882-7974.23.1.24

*Sutter, M., \& Kocher, M. G. (2007). Trust and trustworthiness across different age groups. Games and Economic Behavior, 59, 364-382. https://doi.org/10.1016/j.geb.2006.07.006

*Suzuki, A. (2018). Persistent Reliance on Facial Appearance among Older Adults When Judging Someone's Trustworthiness. Journals of Gerontology - Series B Psychological Sciences and Social Sciences, 73, 573-583. https://doi.org/10.1093/geronb/gbw034

*Suzuki, A., Ueno, M., Ishikawa, K., Kobayashi, A., Okubo, M., \& Nakai, T. (2019). Agerelated differences in the activation of the mentalizing- and reward-related brain regions during the learning of others' trust trustworthiness. Neurobiology of Aging, 73, 1-8. https://doi.org/10.1016/j.neurobiolaging.2018.09.002

*Sweeney, C. D., \& Ceci, S. J. (2014). Deception detection, transmission, and modality in age and sex. Frontiers in Psychology, 5, 1-10. https://doi.org/10.3389/fpsyg.2014.00590

Sze, J. A., Gyurak, A., Goodkind, M. S., \& Levenson, R. (2012). Greater emotional empathy and prosocial behavior in late life. Emotion, 12, 1129-1140. https://doi.org/10.1037/a0025011

United Nations. (2017). World Population Prospects: The 2017 Revision, Key Findings and Advance Tables.

Valentine, J. C., Pigott, T. D., Rothstein, H. R. (2010). How many studies do you need? A primer on statistical power for meta-analysis, Journal of Educational and Behavioral Statistics, 35, 215-247. https://doi.org/10.3102/1076998609346961

Van Lange, P. A. M. (2015). Generalized trust: Four lessons from genetics and culture. Current Directions in Psychological Science, 24, 71-76. https://doi.org/10.1177/0963721414552473

Vaportzis, E., Clausen, M. G., \& Gow, A. J. (2017). Older adults perceptions of technology 
and barriers to interacting with tablet computers: A focus group study. Frontiers in Psychology, 8, 1-11. https://doi.org/10.3389/fpsyg.2017.01687

Viechtbauer, W., \& Cheung, M. W.-L. (2010). Outlier and influence diagnostics for metaanalysis. Research Synthesis Methods, 1, 112-125. https://doi.org/10.1002/jrsm.11

*Webb, B., Hine, A. C., \& Bailey, P. E. (2016). Difficulty in differentiating trustworthiness from untrustworthiness in older age. Developmental Psychology, 52, 985-995. https://doi.org/10.1037/dev0000126

Wilkins, R, \& Lass, I. (2018). The Household, Income and Labour Dynamics in Australia Survey: Selected Findings from Waves 1 to 16. Melbourne Institute: Applied Economic \& Social Research, University of Melbourne.

World Health Organisation. (2015). World report on ageing and health.

*Zebrowitz, L. A., Boshyan, J., Ward, N., Gutchess, A., \& Hadjikhani, N. (2017). The older adult positivity effect in evaluations of trustworthiness: Emotion regulation or cognitive capacity? PLoS ONE, 12, 1-18. https://doi.org/10.1371/journal.pone.0169823

*Zebrowitz, L. A., Franklin, R. G., Hillman, S., \& Boc, H. (2013). Older and younger adults' first impressions from faces: Similar in agreement but different in positivity. Psychology and Aging, 28, 202-212. https://doi.org/10.1037/a0030927

*Zebrowitz, L. A., Ward, N., Boshyan, J., Gutchess, A., \& Hadjikhani, N. (2018). Older adults' neural activation in the reward circuit is sensitive to face trustworthiness. Cognitive, Affective and Behavioral Neuroscience, 18, 21-34. https://doi.org/10.3758/s13415-017-0549-1 
Figure captions

Figure 1. Forest plots of studies assessing trust in response to (A) positive and (B) negative indicators of trustworthiness. A positive effect indicates that older adults are more trusting than young adults, and a negative effect indicates the opposite.

Figure 2. Forest plot of studies assessing behavioral and self-reported trust in response to neutral indicators of trustworthiness. A positive effect indicates that older adults are more trusting than young adults, and a negative effect indicates the opposite. 
Table 1. Characteristics of Studies Contributing to the Meta-Analysis

\begin{tabular}{|c|c|c|c|c|c|c|c|c|c|c|}
\hline \multirow[b]{3}{*}{ Study } & \multicolumn{6}{|c|}{ Participant characteristics } & \multirow{3}{*}{$\begin{array}{l}\text { Cognitive } \\
\text { status }\end{array}$} & \multicolumn{3}{|c|}{ Trust } \\
\hline & \multicolumn{2}{|c|}{ Mean $(S D)$ age } & \multicolumn{2}{|c|}{$n$} & \multicolumn{2}{|c|}{$\%$ male } & & \multirow[b]{2}{*}{ Task } & \multirow[b]{2}{*}{ Response } & \multirow[b]{2}{*}{ Cue } \\
\hline & $\mathrm{Y}$ & $\mathrm{O}$ & $\mathrm{Y}$ & $\mathrm{O}$ & $\mathrm{Y}$ & $\mathrm{O}$ & & & & \\
\hline \multirow{2}{*}{$\begin{array}{l}\text { Bailey et al. } \\
\text { (2015; Study 1) }\end{array}$} & \multirow{2}{*}{$\begin{array}{l}20.31 \\
(2.26)\end{array}$} & \multirow{2}{*}{$\begin{array}{l}70.66 \\
(4.68)\end{array}$} & \multirow[t]{2}{*}{35} & \multirow[t]{2}{*}{32} & \multirow[t]{2}{*}{51} & \multirow[t]{2}{*}{59} & \multirow[t]{2}{*}{ MMSE } & Trust game & Behavioral & $\mathrm{N}$ \\
\hline & & & & & & & & Face rating & Self-report & $\mathrm{N}$ \\
\hline \multirow{2}{*}{$\begin{array}{l}\text { Bailey et al. } \\
\text { (2015; Study 2) }\end{array}$} & \multirow{2}{*}{$\begin{array}{l}22.36 \\
(4.16)\end{array}$} & \multirow{2}{*}{$\begin{array}{l}72.82 \\
(5.34)\end{array}$} & \multirow[t]{2}{*}{61} & \multirow[t]{2}{*}{67} & \multirow[t]{2}{*}{45} & \multirow[t]{2}{*}{49} & \multirow[t]{2}{*}{ MMSE } & Trust game & Behavioral & $\mathrm{N}$ \\
\hline & & & & & & & & Dispositional & Self-report & $\mathrm{N}$ \\
\hline \multirow{5}{*}{$\begin{array}{l}\text { Bailey, Petridis et } \\
\text { al. (2016) }\end{array}$} & \multirow{5}{*}{$\begin{array}{l}22.03 \\
(2.12)\end{array}$} & \multirow{5}{*}{$\begin{array}{l}73.14 \\
(5.97)\end{array}$} & \multirow[t]{5}{*}{34} & \multirow[t]{5}{*}{34} & \multirow[t]{5}{*}{56} & \multirow[t]{5}{*}{50} & \multirow[t]{5}{*}{ MMSE } & Face rating & Self-report & $\mathrm{N}$ \\
\hline & & & & & & & & & & T-R \\
\hline & & & & & & & & & Behavioral & U-R \\
\hline & & & & & & & & Repeated trust game & & T-R \\
\hline & & & & & & & & & Self-report & U-R \\
\hline Bailey, Szczap et & 22.69 & 74.46 & 35 & 35 & 49 & 46 & ACE-R & & & T-R \\
\hline & $(2.71)$ & $(5.97)$ & & & & & & Trust game & Behavioral & U-R \\
\hline Bell et al. (2013) & 22.06 & 70.58 & 93 & 91 & 16 & 37 & DemTect & & & $\mathrm{T}-\mathrm{S}$ \\
\hline & $(2.72)$ & $(5.32)$ & & & & & & Trust game & Behavioral & U-S \\
\hline Bond et al. (2005) & $\begin{array}{l}25 \\
(6.0)\end{array}$ & $\begin{array}{c}66 \\
(5.5)\end{array}$ & 28 & 28 & 50 & 50 & - & Lie detection & Self-report & U-R \\
\hline Cassidy \& & 18.38 & 75.38 & 32 & 32 & 38 & 28 & MMSE & & & $\mathrm{T}-\mathrm{S}$ \\
\hline $\begin{array}{l}\text { Gutchess (2015; } \\
\text { Study 2) }\end{array}$ & $(.91)$ & (7.94) & & & & & & Face rating & Self-report & U-S \\
\hline
\end{tabular}


Table 1 continued

\begin{tabular}{|c|c|c|c|c|c|c|c|c|c|c|}
\hline \multirow[b]{3}{*}{ Study } & \multicolumn{6}{|c|}{ Participant characteristics } & & \multicolumn{3}{|c|}{ Trust } \\
\hline & \multicolumn{2}{|c|}{ Mean $(S D)$ age } & \multicolumn{2}{|c|}{$n$} & \multicolumn{2}{|c|}{$\%$ male } & \multirow{2}{*}{$\begin{array}{c}\text { Cognitive } \\
\text { status }\end{array}$} & \multirow[b]{2}{*}{ Task } & \multirow[b]{2}{*}{ Response } & \multirow[b]{2}{*}{ Cue } \\
\hline & $\mathrm{Y}$ & $\mathrm{O}$ & $\mathrm{Y}$ & $\mathrm{O}$ & $\mathrm{Y}$ & $\mathrm{O}$ & & & & \\
\hline \multirow{4}{*}{$\begin{array}{l}\text { Cassidy et al. } \\
\text { (2018) }\end{array}$} & 18.9 & 71.6 & 44 & 44 & 36 & 34 & MMSE & \multirow{4}{*}{ Face classification } & & T-S \\
\hline & $(2.2)$ & $(6.06)$ & & & & & & & Behavioral & U-S \\
\hline & & & & & & & & & & T-S \\
\hline & & & & & & & & & Self-report & U-S \\
\hline \multirow{4}{*}{$\begin{array}{l}\text { Castle et al. } \\
\text { (2012; Study 1) }\end{array}$} & \multirow{4}{*}{$\begin{array}{l}23.21 \\
(5.09)\end{array}$} & \multirow{4}{*}{$\begin{array}{l}68.76 \\
(6.60)\end{array}$} & \multirow[t]{4}{*}{24} & \multirow[t]{4}{*}{119} & \multirow[t]{4}{*}{-} & \multirow[t]{4}{*}{-} & \multirow[t]{4}{*}{ MMSE } & & & $\mathrm{T}-\mathrm{S}$ \\
\hline & & & & & & & & Face rating & Self-report & $\mathrm{N}$ \\
\hline & & & & & & & & & & U-S \\
\hline & & & & & & & & Dispositional & Self-report & $\mathrm{N}$ \\
\hline \multirow[t]{2}{*}{ Ebner et al. 2018} & \multirow{2}{*}{$\begin{array}{l}21.7 \\
(4.1)\end{array}$} & \multirow{2}{*}{$\begin{array}{c}80 \\
(4.43)\end{array}$} & \multirow[t]{2}{*}{100} & \multirow[t]{2}{*}{16} & \multirow[t]{2}{*}{44} & \multirow[t]{2}{*}{69} & \multirow[t]{2}{*}{ TICS } & Phishing email & Self-report & U-R \\
\hline & & & & & & & & Dispositional & Self-report & $\mathrm{N}$ \\
\hline $\begin{array}{l}\text { General Social } \\
\text { Survey }\end{array}$ & $\begin{array}{l}23.51 \\
(2.7)\end{array}$ & $\begin{array}{l}81.21 \\
(2.7)\end{array}$ & 146 & 58 & 45 & 38 & - & Rating & Self-report & $\mathrm{N}$ \\
\hline \multirow{3}{*}{$\begin{array}{l}\text { Grainger et al. } \\
(2018)\end{array}$} & \multirow{3}{*}{$\begin{array}{l}20.18 \\
(2.5)\end{array}$} & \multirow{3}{*}{$\begin{array}{l}73.37 \\
(6.15)\end{array}$} & \multirow[t]{3}{*}{61} & \multirow[t]{3}{*}{57} & \multirow[t]{3}{*}{46} & \multirow[t]{3}{*}{47} & - & & & T-S \\
\hline & & & & & & & & Face rating & Self-report & $\mathrm{N}$ \\
\hline & & & & & & & & & & U-S \\
\hline
\end{tabular}


Table 1 continued

\begin{tabular}{|c|c|c|c|c|c|c|c|c|c|c|}
\hline \multirow[b]{3}{*}{ Study } & \multicolumn{6}{|c|}{ Participant characteristics } & & \multicolumn{3}{|c|}{ Trust } \\
\hline & \multicolumn{2}{|c|}{ Mean $(S D)$ age } & \multicolumn{2}{|c|}{$n$} & \multicolumn{2}{|c|}{$\%$ male } & \multirow{2}{*}{$\begin{array}{l}\text { Cognitive } \\
\text { status }\end{array}$} & \multirow[b]{2}{*}{ Task } & \multirow[b]{2}{*}{ Response } & \multirow[b]{2}{*}{ Cue } \\
\hline & $\mathrm{Y}$ & $\mathrm{O}$ & $\mathrm{Y}$ & $\mathrm{O}$ & $\mathrm{Y}$ & $\mathrm{O}$ & & & & \\
\hline \multirow{4}{*}{$\begin{array}{l}\text { Ho et al. (2005; } \\
\text { Study 1) }\end{array}$} & 20.73 & 66.93 & 13 & 12 & 31 & 25 & MMSE & \multirow{4}{*}{ Technology } & & T-R \\
\hline & $(1.68)$ & $(6.29)$ & & & & & & & Self-report & U-R \\
\hline & \multirow{6}{*}{$\begin{array}{c}22 \\
(3.79)\end{array}$} & \multirow{6}{*}{$\begin{array}{l}67.67 \\
(4.38)\end{array}$} & \multirow{6}{*}{12} & \multirow{6}{*}{12} & \multirow{6}{*}{42} & \multirow{6}{*}{33} & \multirow{6}{*}{ MMSE } & & \multirow{2}{*}{ Behavioral } & T-R \\
\hline & & & & & & & & & & U-R \\
\hline \multirow{4}{*}{$\begin{array}{l}\text { Ho et al. (2005; } \\
\text { Study 2) }\end{array}$} & & & & & & & & \multirow{4}{*}{ Technology } & \multirow[b]{2}{*}{ Self-report } & T-R \\
\hline & & & & & & & & & & U-R \\
\hline & & & & & & & & & \multirow[b]{2}{*}{ Behavioral } & T-R \\
\hline & & & & & & & & & & U-R \\
\hline $\begin{array}{l}\text { Holm \& Nystedt } \\
\text { (2005) }\end{array}$ & $\begin{array}{l}20 \\
(0)\end{array}$ & $\begin{array}{l}70 \\
(0)\end{array}$ & 25 & 14 & 60 & 60 & - & Trust game & Behavioral & $\mathrm{N}$ \\
\hline Josef et al. (2016) & $18-27$ & $78-87$ & 73 & 35 & 53 & 40 & - & Trust game & Behavioral & $\mathrm{N}$ \\
\hline $\begin{array}{l}\text { Kiiski et al. } \\
\text { (2016) }\end{array}$ & 22.8 & 70.9 & 65 & 46 & 32 & 37 & - & Face ratings & Self-report & $\mathrm{N}$ \\
\hline \multirow{2}{*}{$\begin{array}{l}\text { Kircanski et al. } \\
\text { (2018) }\end{array}$} & \multirow{2}{*}{$\begin{array}{l}34.52 \\
(3.16)\end{array}$} & \multirow{2}{*}{$\begin{array}{l}73.3 \\
(5.2)\end{array}$} & \multirow[t]{2}{*}{110} & \multirow[t]{2}{*}{112} & \multirow[t]{2}{*}{36} & \multirow[t]{2}{*}{39} & \multirow[t]{2}{*}{ MMSE } & Intention & \multirow[b]{2}{*}{ Self-report } & \multirow[b]{2}{*}{ U-R } \\
\hline & & & & & & & & & & \\
\hline $\begin{array}{l}\text { Komeda et al. } \\
\text { (2018) }\end{array}$ & 25.7 & 63.6 & 100 & 100 & 50 & 50 & - & Dispositional & Self-report & $\mathrm{N}$ \\
\hline
\end{tabular}


Table 1 continued

\begin{tabular}{|c|c|c|c|c|c|c|c|c|c|c|}
\hline \multirow[b]{3}{*}{ Study } & \multicolumn{6}{|c|}{ Participant characteristics } & & \multicolumn{3}{|c|}{ Trust } \\
\hline & \multicolumn{2}{|c|}{ Mean $(S D)$ age } & \multicolumn{2}{|c|}{$n$} & \multicolumn{2}{|c|}{$\%$ male } & \multirow{2}{*}{$\begin{array}{l}\text { Cognitive } \\
\text { status }\end{array}$} & \multirow[b]{2}{*}{ Task } & \multirow[b]{2}{*}{ Response } & \multirow[b]{2}{*}{$\mathrm{Cue}$} \\
\hline & $\mathrm{Y}$ & $\mathrm{O}$ & $\mathrm{Y}$ & $\mathrm{O}$ & $\mathrm{Y}$ & $\mathrm{O}$ & & & & \\
\hline \multirow[t]{2}{*}{ Pak et al. (2012) } & \multirow{2}{*}{$\begin{array}{l}19.82 \\
(1.54)\end{array}$} & \multirow{2}{*}{$\begin{array}{l}72.98 \\
(5.18)\end{array}$} & \multirow[t]{2}{*}{45} & \multirow[t]{2}{*}{45} & \multirow[t]{2}{*}{56} & \multirow[t]{2}{*}{38} & \multirow[t]{2}{*}{-} & \multirow[b]{2}{*}{ Technology } & Behavioral & $\mathrm{N}$ \\
\hline & & & & & & & & & Self-report & $\mathrm{N}$ \\
\hline \multirow[t]{2}{*}{ Pak et al. (2017) } & \multirow{2}{*}{$\begin{array}{l}18.8 \\
(1.0)\end{array}$} & \multirow{2}{*}{$\begin{array}{l}70.5 \\
(4.0)\end{array}$} & \multirow[t]{2}{*}{59} & \multirow[t]{2}{*}{36} & \multirow[t]{2}{*}{-} & \multirow[t]{2}{*}{-} & \multirow[t]{2}{*}{-} & & & T-R \\
\hline & & & & & & & & Technology & Self-report & U-R \\
\hline \multirow{4}{*}{$\begin{array}{l}\text { Petrican et al. } \\
\text { (2013) }\end{array}$} & \multirow{4}{*}{$\begin{array}{l}21.31 \\
(3.74)\end{array}$} & \multirow{4}{*}{$\begin{array}{c}70.35 \\
(5.8)\end{array}$} & \multirow[t]{4}{*}{63} & \multirow[t]{4}{*}{69} & \multirow[t]{4}{*}{38} & \multirow[t]{4}{*}{38} & \multirow[t]{4}{*}{-} & & & $\mathrm{T}-\mathrm{S}$ \\
\hline & & & & & & & & Face rating & Self-report & U-S \\
\hline & & & & & & & & & & $\mathrm{T}-\mathrm{S}$ \\
\hline & & & & & & & & Gaze following & Behavioral & U-S \\
\hline Rasmussen \& & 19.33 & 80.45 & 30 & 31 & 63 & 42 & MMSE & & & T-R \\
\hline Gutchess (2018) & (1.67) & $(6.2)$ & & & & & & Repeated trust game & Behavioral & $\mathrm{N}$ \\
\hline & & & & & & & & & & U-R \\
\hline $\begin{array}{l}\text { Rieger \& Mata } \\
\text { (2013) }\end{array}$ & $17-30$ & $71+$ & 18 & 56 & 94 & 95 & - & Trust game & Behavioral & $\mathrm{N}$ \\
\hline Ruffman et al. & $17-26$ & $60-89$ & 30 & 27 & 40 & 50 & MMSE & & & T-R \\
\hline (2012) & & & & & & & & Lie detection & Self-report & U-R \\
\hline $\begin{array}{l}\text { Schniter \& } \\
\text { Shields (2014) }\end{array}$ & $\begin{array}{c}18.89 \\
(1.1)\end{array}$ & $\begin{array}{c}70.11 \\
(10.05)\end{array}$ & 20 & 20 & 45 & 65 & - & $\begin{array}{l}\text { Bluff-Challenge } \\
\text { game }\end{array}$ & Behavioral & $\mathrm{N}$ \\
\hline
\end{tabular}


Table 1 continued

\begin{tabular}{|c|c|c|c|c|c|c|c|c|c|c|}
\hline \multirow[b]{3}{*}{ Study } & \multicolumn{6}{|c|}{ Participant characteristics } & & \multicolumn{3}{|c|}{ Trust } \\
\hline & \multicolumn{2}{|c|}{ Mean $(S D)$ age } & \multicolumn{2}{|c|}{$n$} & \multicolumn{2}{|c|}{$\%$ male } & \multirow{2}{*}{$\begin{array}{l}\text { Cognitive } \\
\text { status }\end{array}$} & \multirow[b]{2}{*}{ Task } & \multirow[b]{2}{*}{ Response } & \multirow[b]{2}{*}{$\mathrm{Cue}$} \\
\hline & $\mathrm{Y}$ & $\mathrm{O}$ & $\mathrm{Y}$ & $\mathrm{O}$ & $\mathrm{Y}$ & $\mathrm{O}$ & & & & \\
\hline \multirow{4}{*}{$\begin{array}{l}\text { Slessor et al. } \\
\text { (2014) }\end{array}$} & 19.73 & 72.04 & 40 & 47 & 68 & 66 & MMSE & & & T-R \\
\hline & $(2.74)$ & $(6.14)$ & & & & & & Lie detection & Self-report & U-R \\
\hline & & & & & & & & & & T-R \\
\hline & & & & & & & & Liar Rating & Self-report & U-R \\
\hline \multirow{2}{*}{$\begin{array}{l}\text { Stanley \& } \\
\text { Blanchard-Fields } \\
\text { (2008) } \\
\text { Sutter \& Kocher } \\
(2007)\end{array}$} & $\begin{array}{c}20.6 \\
(1.55)\end{array}$ & $\begin{array}{l}70.72 \\
(5.36)\end{array}$ & 171 & 193 & 50 & 50 & - & Lie detection & Self-report & U-R \\
\hline & $\begin{array}{c}22 \\
(2.8)\end{array}$ & $\begin{array}{c}68 \\
(8.6)\end{array}$ & 55 & 17 & 52 & 24 & - & Trust game & Behavioral & $\mathrm{N}$ \\
\hline \multirow[t]{5}{*}{ Suzuki (2018) } & 21.53 & 69.47 & 34 & 34 & 44 & 47 & MMSE & & & T-S \\
\hline & $(2.89)$ & $(4.14)$ & & & & & & Face rating & Self-report & U-S \\
\hline & & & & & & & & & & T-R \\
\hline & & & & & & & & Repeated trust game & Behavioral & U-R \\
\hline & & & & & & & & Dispositional & Self-report & $\mathrm{N}$ \\
\hline \multirow{2}{*}{$\begin{array}{l}\text { Suzuki et al. } \\
\text { (2019) }\end{array}$} & 22.21 & 69.86 & 24 & 22 & 54 & 50 & MMSE & & & T-S \\
\hline & $(3.39)$ & $(3.51)$ & & & & & & Face classification & Self-report & U-S \\
\hline $\begin{array}{l}\text { Sweeney \& Ceci } \\
\text { (2014) }\end{array}$ & $\begin{array}{l}19.58 \\
(1.25)\end{array}$ & $\begin{array}{l}73.77 \\
(7.79)\end{array}$ & 84 & 77 & 51 & 51 & MMSE & Lie detection & Self-report & U-R \\
\hline
\end{tabular}


Table 1 continued

\begin{tabular}{|c|c|c|c|c|c|c|c|c|c|c|}
\hline \multirow[b]{3}{*}{ Study } & \multicolumn{6}{|c|}{ Participant characteristics } & & \multicolumn{3}{|c|}{ Trust } \\
\hline & \multicolumn{2}{|c|}{ Mean $(S D)$ age } & \multicolumn{2}{|c|}{$n$} & \multicolumn{2}{|c|}{$\%$ male } & \multirow{2}{*}{$\begin{array}{l}\text { Cognitive } \\
\text { status }\end{array}$} & \multirow[b]{2}{*}{ Task } & \multirow[b]{2}{*}{ Response } & \multirow[b]{2}{*}{$\mathrm{Cu}$} \\
\hline & $\bar{Y}$ & $\mathrm{O}$ & $\mathrm{Y}$ & $\mathrm{O}$ & $\mathrm{Y}$ & $\mathrm{O}$ & & & & \\
\hline \multirow{4}{*}{$\begin{array}{l}\text { Webb et al. } \\
\text { (2016) }\end{array}$} & 20.91 & 74.45 & 34 & 31 & 49 & 48 & MMSE & \multirow{4}{*}{ Repeated trust game } & & $\mathrm{T}-\mathrm{R}$ \\
\hline & $(3.58)$ & $(6.59)$ & & & & & & & Behavioral & U-R \\
\hline & & & & & & & & & Self-report & T-R \\
\hline & & & & & & & & & & U-R \\
\hline World Values & 22.60 & 81.19 & 21,323 & 1,775 & 50 & 45 & - & Rating & Self-report & $\mathrm{N}$ \\
\hline Survey & $(2.83)$ & $(2.50)$ & & & & & & & & \\
\hline \multirow{3}{*}{$\begin{array}{l}\text { Zebrowitz et al. } \\
\text { (2013) }\end{array}$} & \multirow{3}{*}{$\begin{array}{l}18.8 \\
(1.0)\end{array}$} & \multirow{3}{*}{$\begin{array}{l}76.3 \\
(6.4)\end{array}$} & \multirow[t]{3}{*}{48} & \multirow[t]{3}{*}{48} & \multirow[t]{3}{*}{48} & \multirow[t]{3}{*}{50} & \multirow[t]{3}{*}{ MMSE } & & & T-S \\
\hline & & & & & & & & Face rating & Self-report & $\mathrm{N}$ \\
\hline & & & & & & & & & & U-S \\
\hline $\begin{array}{l}\text { Zebrowitz (2017; } \\
\text { Study 1) }\end{array}$ & $\begin{array}{l}25.35 \\
(4)\end{array}$ & $\begin{array}{l}76.89 \\
(7.18)\end{array}$ & 20 & 20 & 50 & 50 & MMSE & Face rating & Self-report & $\mathrm{N}$ \\
\hline \multirow{3}{*}{$\begin{array}{l}\text { Zebrowitz (2017; } \\
\text { Study 2) }\end{array}$} & \multirow{3}{*}{$\begin{array}{l}23.96 \\
(3.01)\end{array}$} & \multirow{3}{*}{$\begin{array}{l}72.96 \\
(7.36)\end{array}$} & \multirow[t]{3}{*}{23} & \multirow[t]{3}{*}{23} & \multirow[t]{3}{*}{52} & \multirow[t]{3}{*}{52} & \multirow[t]{3}{*}{ MMSE } & & & $\mathrm{T}-\mathrm{S}$ \\
\hline & & & & & & & & Face rating & Self-report & $\mathrm{N}$ \\
\hline & & & & & & & & & & U-S \\
\hline \multirow{3}{*}{$\begin{array}{l}\text { Zebrowitz et al. } \\
(2018)\end{array}$} & \multirow{3}{*}{$\begin{array}{l}24.08 \\
(3.01)\end{array}$} & \multirow{3}{*}{$\begin{array}{l}72.83 \\
(7.22)\end{array}$} & \multirow[t]{3}{*}{23} & \multirow[t]{3}{*}{24} & \multirow[t]{3}{*}{50} & 54 & MMSE & & & $\mathrm{T}-\mathrm{S}$ \\
\hline & & & & & & & & Face rating & Self-report & $\mathrm{N}$ \\
\hline & & & & & & & & & & U-S \\
\hline
\end{tabular}


Note. Cognitive status: ACE-R refers to Addenbrooke's Cognitive Examination Revised; MMSE refers to Mini-Mental State Examination; TICS refers to Telephone Interview for Cognitive Status. Trust cue: $\mathrm{N}$ refers to a neutral cue to trustworthiness; T-S refers to trustworthy and superficial; T-R refers to trustworthy and reliable; U-S refers to untrustworthy and superficial; U-R refers to untrustworthy and reliable. Where $M$ and $S D$ were not available for age, age range is provided. 
Table 2. Number of effects contributing to each moderator level.

\begin{tabular}{lccc}
\cline { 2 - 4 } Moderator & \multicolumn{3}{c}{ Indicator of trustworthiness } \\
\cline { 2 - 4 } & Positive & Negative & Neutral \\
\hline Reliability & & & \\
$\quad$ Superficial & 11 & 11 & - \\
Reliable & 10 & 14 & - \\
Type of trust & & & \\
Financial & 6 & 6 & 7 \\
$\quad$ Non-financial & 17 & 22 & 16 \\
Type of response & & & \\
Self-report & 17 & 22 & 15 \\
Behavioral & 10 & 10 & 9 \\
\hline
\end{tabular}


(A)

(B)

$\underline{\text { Study }}$

Hedges's $\mathrm{g}$ and $95 \% \mathrm{Cl}$

Study

Hedges's g and $95 \% \mathrm{Cl}$

Bailey, Petridis et al. (2016)

Bailey, Szczap et al. (2016)

Bell et al. (2013)

Cassidy \& Gutchess (2015, Study 2) Cassidy et al. (2018)

Castle et al. (2012, Study 1)

Grainger et al. (2018)

Ho et al. (Study 1)

Ho et al. (Study 2)

Pak et al. (2017)

Petrican et al. (2013)

Rasmussen \& Gutchess (2018)

Ruffman et al. (2012)

Slessor et al. (2014)

Suzuki (2018)

Suzuki et al. (2019)

Webb et al. (2016)

Zebrowitz et al. (2013)

Zebrowitz et al. (2017, Study 2)

Zebrowitz et al. (2018)

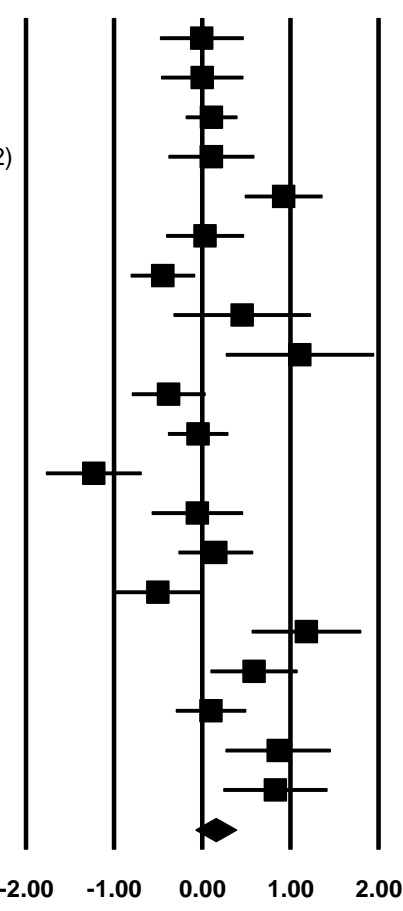

Bailey, Petridis et al. (2016)

Bailey, Szczap et al. (2016)

Bell et al. (2013)

Bond et al. (2005)

Cassidy \& Gutchess (2015, Study 2)

Cassidy et al. (2018)

Castle et al. (2012, Study 1)

Ebner et al. (2018)

Grainger et al. (2018)

Ho et al. (2005, Study 1)

Ho et al. (2005, Study 2)

Kircanski et al. (2018)

Pak et al. (2017)

Petrican et al. (2013)

Rasmussen \& Gutchess (2018)

Ruffman et al. (2012)

Slessor et al. (2014)

Stanley \& Blachard-Fields (2008)

Suzuki (2018)

Suzuki et al. (2019)

Sweeney \& Ceci (2014)

Webb et al. (2016)

Zebrowitz et al. (2013)

Zebrowitz et al. (2017, Study 2)

Zebrowitz et al. (2018)

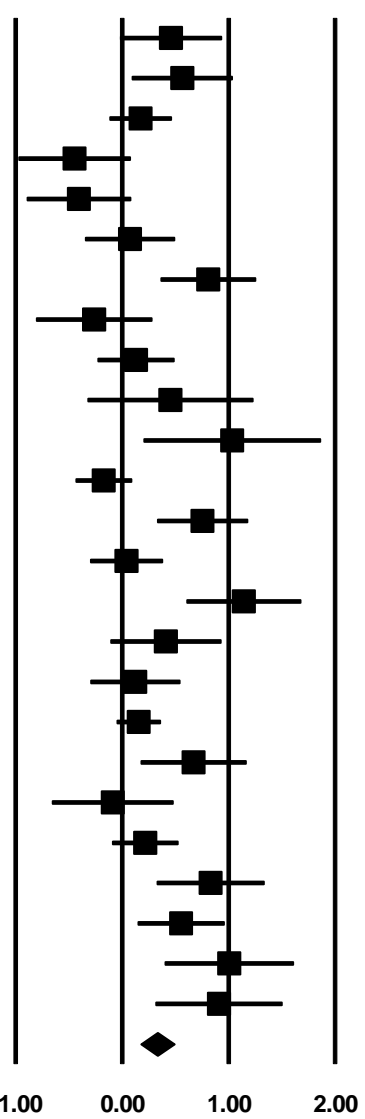

Fig. 1 
Study

Bailey et al. (2015, Study 1) Bailey et al. (2015, Study 2) Holm \& Nystedt (2005)

Josef et al. (2016)

Pak et al. (2012)

Rasmussen \& Gutchess (2018)

Rieger \& Mata (2013)

Schniter \& Shields (2014)

Sutter \& Kocher (2007)

Bailey et al. (2015, Study 1)

Bailey et al. (2015, Study 2)

Bailey, Petridis et al. (2016)

Castle et al. (2012, Study 1)

Ebner et al. (2018)

General Social Survey

Grainger et al. (2018)

Kiiski et al. (2016)

Komeda et al. (2018)

Pak et al. (2012)

Suzuki (2018)

World Values Survey

Zebrowitz et al. (2013)

Zebrowitz (2017, Study 1)

Zebrowitz et al. (2018)
Response

Hedges's g and $95 \% \mathrm{Cl}$

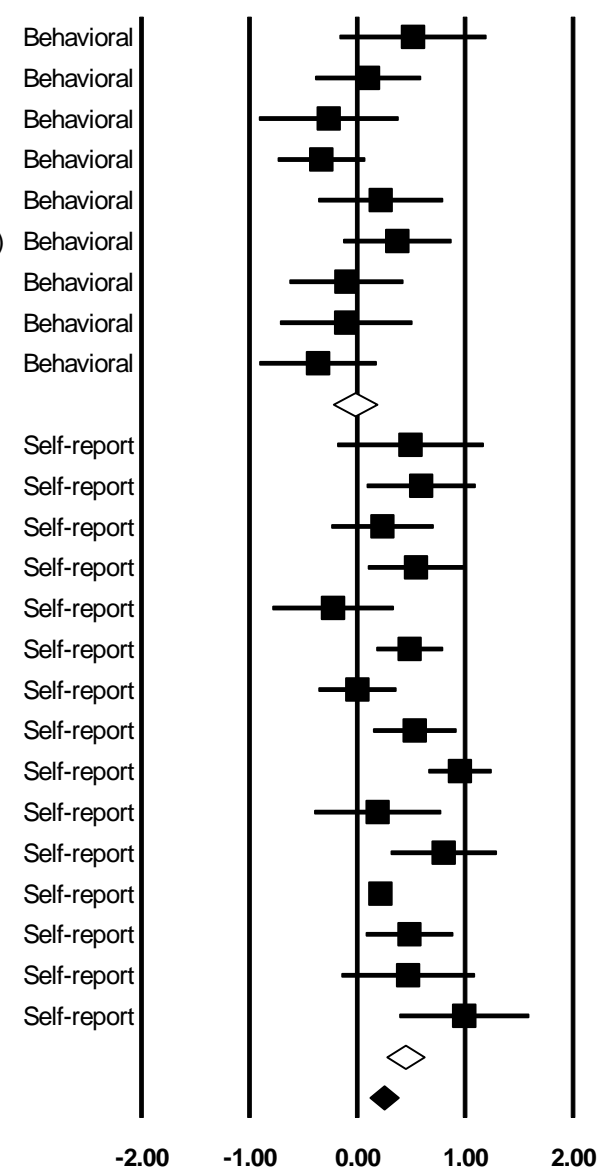

Fig. 2 